\title{
Efeito do bebedouro e da densidade no desempenho de frangos alojados em alta temperatura
}

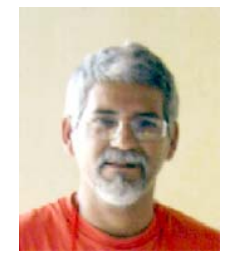

\author{
José H.V. Silva ${ }^{1}$, José Jordão Filho², Edson L. Silva ${ }^{3}$, Marcelo L. G. Ribeiro² \& Dermeval A. Furtado ${ }^{4}$ \\ ${ }^{1}$ DAP/CFT/UFPB. CEP 58.220-000. Bananeiras, PB. Fone (83) 3367-1200. jvilar@cft.ufpb.br (Foto) \\ 2 PDIZ/UFPB/UFRPE/UFC. CEP 58 397-000, Areia,PB. Fone: (83) 3362-2300. jjfilho@yahoo.com.br \\ ${ }^{3}$ UFLA/DZ, CEP 37200-000. Lavras,MG. edsonl@yahoo.com.br \\ ${ }^{4}$ DEAg/UFCG. CEP 58109-970. Campina Grande,PB. Fone: (83) 3310-1486. dermeval@deag.ufcg.
}

Protocolo 53 - 28/4/2004 - Aprovado em 26/6/2005

\begin{abstract}
Resumo: Com o objetivo de avaliar o efeito do bebedouro pendular (BP) e do bebedouro alternativo (BALT), e de diferentes densidades (10 e 14 aves $\mathrm{m}^{-2}$ ) sobre o desempenho de 240 frangos de corte de 12 a 18, 19 a 38 e de 39 a 46 dias de idade, realizou-se este experimento em condições de temperatura média de $27,6{ }^{\circ} \mathrm{C}$ e umidade relativa de $70,4 \%$, no qual foi utilizado um delineamento inteiramente casualizado em esquema fatorial $2 \times 2$ (dois bebedouros $x$ duas densidades), resultando em quatro tratamentos constituídos de cinco repetições de 10 aves. $O$ BALT foi desenvolvido com base no conceito de amplo espaço de calha circular e alta profundidade de lâmina de água $(5 \mathrm{~cm})$ para permitir a imersão do bico e das faces da ave. $\mathrm{Na}$ alimentação das aves, foram utilizadas rações comerciais, cujo consumo (CR) caiu, enquanto a conversão alimentar (CA) melhorou, quando o BALT foi empregado de 12 a 18 dias. Não houve efeito do bebedouro sobre o CR, ganho de peso (GP) e CA no período total. A D14 (14 aves $\mathrm{m}^{-2}$ ) afetou o GP e o CR de 19 a 38 e de 39 a 46 dias e também no período total, mas a CA não foi alterada. O BALT não afeta o desempenho de frangos de corte, podendo ser usado como opção de baixo custo ao BP. A análise econômica pelo índice de rentabilidade relativa mostrou que o BALT e a D14 oferecem 1 e $5,9 \%$ de retorno a mais que o BP e a D10, (10 aves $\mathrm{m}^{-2}$ ) respectivamente.
\end{abstract}

Palavras-chave: tipos de bebedouro, desempenho avícola, estresse calórico

\section{Effect of type of water facility and density on performance of broiler reared in hot-climate}

\begin{abstract}
The experiment was undertaken in conditions of average temperature of $27.6{ }^{\circ} \mathrm{C}$ and relative humidity of $70.4 \%$, with the objective to evaluate bell (BD) and alternative (ALT) water facility and stocking densities (SD) of 10 and 14 broilers $\mathrm{m}^{-2}$ (SD10 and SD14), on performance of 240 broiler chickens of 12 to 18,19 to 38 and 39 to 46 days of age, allotted in boxes in a completely randomized design in $2 \times 2$ factorial arrangement (two types of drinking facility and two stocking densities), resulting in four treatments, each one with five replications of ten birds. The ALT was developed based on concept of wide and deep water level $(5 \mathrm{~cm})$ permitting not only the beak, but also entire face to be immersed. For the feeding of birds, commercial diets were utilized. The feed intake (FI) decreased, while the feed conversion ratio (FC) improved when the ALT was utilized from 12 to 18 days. There was no effect of drinking facility on Fl, weight gain (WG) and FC in the entire period. The SD14 decreased FI and WG from 19 to 38 and from 39 to 46 days of age, and total period, but the FC was not affected. The ALT did not affect the broiler performance and may be used as an option of low cost in comparison with bell water facility. The economic analysis on income relative index basis showed that the ALT and SD14 offer 1 and $5.9 \%$ better income return than $\mathrm{BD}$ and SD10, respectively.
\end{abstract}

Key words: types of drinker, broiler performance, stress caloric

\section{INTRODUÇÃO}

$\mathrm{O}$ ambiente que envolve as aves tem sido apontado como o grande responsável pelos resultados produtivos da avicultura moderna. O fato é que os conhecimentos de nutrição, fisiologia e genética já chegaram em níveis em que encontram suas limitações na inadequação das instalações (Näas, 1995) e equipamentos que, muitas vezes, são mal projetados para os animais criados em climas tropicais.

Para Baeta \& Souza (1997), um ambiente é confortável para 
aves adultas quando apresenta temperaturas de 18 a $25^{\circ} \mathrm{C}$ e umidade relativa do ar de 50 a $70 \%$. Mota (2001) sugere um ambiente para frangos com temperatura entre 17 e $21^{\circ} \mathrm{C}$ e umidade relativa entre 50 e $80 \%$. A temperatura considerada ideal para o desenvolvimento de frangos de corte é gradualmente reduzida, de $32{ }^{\circ} \mathrm{C}$ na primeira semana de vida para $30^{\circ} \mathrm{C}$ na segunda semana, $28^{\circ} \mathrm{C}$ na terceira semana, $25^{\circ} \mathrm{C}$ na quarta semana, $24{ }^{\circ} \mathrm{C}$ na quinta semana e da sexta semana em diante a temperatura deve ficar igual ou abaixo dos $22{ }^{\circ} \mathrm{C}$ (Yalcin et al., 1997; Rostagno, 1995).

Em virtude da tendência atual de expansão da criação de aves nas regiões quentes do planeta (Balnave, 2004), novas tecnologias em equipamento precisam ser desenvolvidas e testadas nessas condições, visto que a indústria se tem voltado mais para o desenvolvimento de alternativas tecnológicas aplicadas às condições de criação em ambientes de temperaturas amenas (Silva et al., 2004).

Durante o verão, dados de uma grande empresa de integração paraibana indicaram que os frangos em idade de retirada utilizando-se bebedouros nipple de baixo fluxo como fonte de água, eram $150 \mathrm{~g}$ mais leves que aqueles tendo os bebedouros pendulares como fonte de água (Silva et al., 2004).

Segundo Daghir (1995) à medida que o calor aumenta, várias respostas são enfocadas pelo organismo das aves para aumentar a dissipação e reduzir a sobrecarga de calor corporal; imediatamente, as aves aumentam a ingestão de água e atrasam a redução do consumo voluntário, refletindo nas taxas de sobrevivência e de desempenho final de frangos de corte. De acordo com Ribeiro et al. (2004) o consumo de água contribui para o controle da temperatura corporal em aves e esforços devem ser feitos para se obter soluções de baixo custo que permitam amenizar o efeito deletério do estresse pelo calor sobre o desempenho dos frangos de corte.

A ingestão de água e a perda de calor latente se destacam como meios eficientes de controle da homeotermia em frangos de corte em condições de estresse pelo calor; estima-se uma perda de $0,55 \mathrm{kcal} \mathrm{mL}^{-1}$ de água evaporada pelas vias respiratórias (Bampi, 1994). O aumento da temperatura e da densidade de alojamento (Macari, 1996), além de elevar a ingestão de água reduz o consumo de ração em frangos de corte. Segundo Bampi (1994), este fato acarreta baixo peso corporal em relação ao peso normal da linhagem e piora a conversão alimentar podendo, ainda, aumentar a taxa de mortalidade das aves.

De acordo com Macari (1996) a disponibilidade de água é fator preponderante para o desenvolvimento de frangos de corte durante o estresse calórico, pois a água tem papel fundamental nos mecanismos refrigeradores envolvidos na termorregulação. Cuidados especiais de manejo devem ser observados durante o estresse, principalmente associados à qualidade da água e à sua temperatura, visto que o papel mais importante da água durante o estresse é a perda de calor, seja através do processo evaporativo, respiratório ou da pele, e a temperatura da água afeta, obviamente, o seu consumo. As necessidades de água para frangos de corte variam com as estações do ano, temperatura, peso da ave e estágio de produção.

Vários recursos podem ser empregados objetivando-se rendimentos satisfatórios de frangos em condições de estresse pelo calor, como manipulação nutricional da dieta, uso de equipamentos para alterar artificialmente as variáveis climáticas, alterações nas construções, plantio de árvores para aumentar o fluxo de ar pelas instalações, programa de luz e tipo de equipamento usado na distribuição de água às aves.

Estudos têm mostrado que o tipo de bebedouro em condições de alta temperatura pode afetar o consumo de água por parte das aves e, conseqüentemente, o seu desempenho. Segundo Macari (1996), os produtores têm reclamado do custo de instalação e do baixo desempenho do lote, quando a temperatura é superior a $30^{\circ} \mathrm{C}$, com perda de 50 a $100 \mathrm{~g}$ de peso por ave, com uso do bebedouro tipo nipple de baixo fluxo $(0,4$ $\mathrm{mL} \mathrm{s}^{-1}$ ). Este resultado é corroborado por Silva et al. (2004) que, ao testarem três bebedouros (nipple, pendular e alternativo), concluíram que o bebedouro nipple afetou o ganho de peso das aves de 1 a 21 dias em relação aos outros dois tipos de bebedouro.

O bebedouro pendular tem sido largamente usado na avicultura, pelo baixo custo, facilidade de manejo e por resultar em melhor qualidade de cama para a venda, após a retirada do lote, em relação ao bebedouro tipo calha; entretanto, o uso do bebedouro pendular traz dois sérios inconvenientes para o consumo de água, que podem afetar o bem-estar e o desempenho das aves; o reduzido espaço de calha e a lâmina d'água excessivamente baixa, que podem ser agravados pelo manejo inadequado.

Segundo Silva et al. (2004), o bebedouro alternativo apresenta as seguintes características, como diferencial do bebedouro pendular: possibilidade de instalação em posição inferior no galpão, contribuindo para o menor aquecimento da água pelo calor irradiado do telhado, maior espaço e maior profundidade de calha disponível por ave e relação de 20 aves adultas por bebedouro, inferior ao pendular ( 80 aves).

A possibilidade de se trabalhar com densidade acima de 10 aves $\mathrm{m}^{-2}$ na época quente, surge como estratégia de produção, podendo trazer resultados financeiros compensadores para os avicultores e, segundo Mathur \& Horst (1994) a realização de testes sob condições naturais fornece informação mais útil para a compreensão de um clima específico que aqueles de experimentos em ambientes controlados.

Objetivou-se, com o presente trabalho, avaliar o efeito do bebedouro alternativo (BALT) versus bebedouro pendular (BP) e de duas densidades de alojamento sobre o desempenho de frangos de corte durante a estação quente, no Nordeste brasileiro.

\section{MATERIAL E MÉTODOS}

O experimento foi conduzido no Laboratório Avícola do Centro de Formação de Tecnólogos da UFPB, de 5 de outubro a 11 de novembro de 2003. Utilizou-se um lote misto de 240 frangos de corte, com 12 dias de idade e peso vivo médio inicial de $240 \mathrm{~g}$. As aves foram pesadas individualmente e distribuídas em boxes com área de $1 \mathrm{~m}^{2}$. O delineamento experimental foi o inteiramente casualizado, em arranjo fatorial $2 \times 2$ (dois bebedouros e duas densidades), resultando em quatro tratamentos constituídos de seis repetições, cada uma com dez aves. 
Os bebedouros testados são mostrados na Figura 1, bebedouro pendular (BP) e o alternativo (BALT), enquanto as densidades utilizadas foram de 10 e 14 aves $\mathrm{m}^{-2}$. O bebedouro alternativo foi desenvolvido com base no conceito de calha circular ampla e lâmina d'água, suficientemente alta para permitir a imersão do bico e das faces da ave no interior do bebedouro. O galpão utilizado apresenta estrutura de alvenaria com cobertura de telhas de barro em duas águas, orientação LesteOeste e pé direito de 1,80 m, dimensionado em $56 \mathrm{~m}^{2}$ (3,5 m x 16 m) de área.

A.

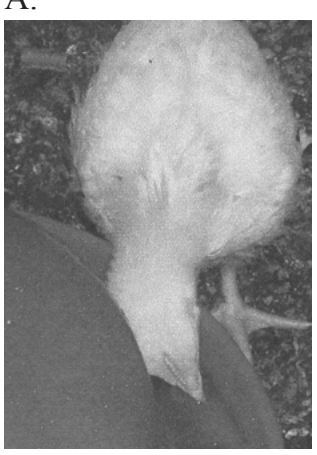

Figura 1. Modelo dos bebedouros pendular convencional (A) e alternativo (B)

As variáveis estudadas foram: consumo de ração (CR), ganho de peso (GP), conversão alimentar (CA) e mortalidade do lote nos períodos de 12-18; 19-38 e de 39-46 dias de idade. No final do experimento duas aves por parcela foram submetidas a um jejum de sólidos de quatro horas de duração e, depois, abatidas para as avaliações de rendimento de carcaça em relação ao peso vivo, rendimento dos cortes (peito, coxa e sobrecoxa) e de gordura abdominal em relação ao peso da carcaça eviscerada com pés e cabeça, além da moela e coração. A gordura abdominal foi considerada o tecido adiposo retirado da cavidade abdominal.

As aves foram alimentadas com ração comercial contendo 20,50, 19,50 e 18,00\% de proteína bruta e 3.000, 3.200 e 3.240 kcal de energia metabolizável, respectivamente, nos primeiro, segundo e terceiro períodos experimentais. Dados de temperatura e umidade relativa do ar foram coletados diariamente, de um aparelho termo-higrômetro instalado no interior de um box, na altura do dorso das aves e utilizado para se obter as médias. Empregou-se um programa de luz de 16 h, considerando-se iluminação natural e artificial.

Realizaram-se as análises estatísticas através do software SAEG - Sistema de Análise Estatística e Genética, versão 7.1, desenvolvido pela Universidade Federal de Viçosa - UFV (2000), adotando-se o teste Tukey, a 5\% de probabilidade para comparação das médias.

A análise econômica foi adaptada de Guidoni (1994), considerando-se apenas o custo de arraçoamento, que representa aproximadamente $75 \%$ do custo de produção de frangos de corte e a receita bruta obtida com a venda das aves. A análise foi realizada para o período de 12 a 46 dias de idade, tendo-se em conta o valor pago pelo peso vivo do frango no Estado da Paraíba, de R $\$ 2,30 \mathrm{~kg}^{-1}$ (US\$ $0,78 \mathrm{~kg}^{-1}$ ) e o preço da ração, de $\mathrm{R} \$ 0,80 \mathrm{~kg}^{-1}$ (US\$ 0,273 $\mathrm{kg}^{-1}$ ). Na realização desta análise utilizaram-se as seguintes variáveis:

Renda bruta média (RBM) que representa o total recebido em função do valor de venda (VV) da ave, em relação ao ganho de peso (GP) no período de 12 a 46 dias.

$$
\mathrm{RBM}=\mathrm{VV} \times \mathrm{GP}\left(\mathrm{R} \$ \mathrm{~kg}^{-1} \text { de carne }\right)
$$

O custo médio de arraçoamento (CMA) indica o custo total relativo ao consumo médio de ração, em função do período de 12 a 46 dias.

$$
\mathrm{CMA}=\mathrm{CR} \times \mathrm{PR}\left(\mathrm{R} \$ \mathrm{~kg}^{-1} \text { de ração }\right)
$$

em que:

CR - consumo de ração

PR - preço do kg de ração

A margem bruta média (MBM), em $\mathrm{R} \$$ ave $^{-1}$, que representa a diferença entre a renda bruta média (RBM) e o custo médio de arraçoamento (CMA).

$$
\mathrm{MBM}=\mathrm{RBM}-\mathrm{CMA}
$$

A rentabilidade média (RM), em porcentagem, representa o quociente entre a margem bruta (MBM) e o custo de arraçoamento (CMA), indicando a rentabilidade obtida em função do investimento em ração, ou seja:

$$
\mathrm{RM}=\frac{\mathrm{MBM}}{\mathrm{CMA}} \times 100(\%)
$$

O índice de rentabilidade relativa (IRR) indica a relação entre a RM dos tratamentos com bebedouro alternativo nas duas densidades populacionais em relação aos tratamentos com bebedouro pendular na densidade de 10 aves $\mathrm{m}^{-2}$ (controle) e da densidade de 14 aves $\mathrm{m}^{-2}$ quanto a densidade de 10 aves $\mathrm{m}^{-2}$ (testemunha). O IRR é definido por:

$$
\mathrm{IRR}=\frac{\mathrm{RM} \text { do tratamento }}{\mathrm{RM} \text { do controle }} 100(\%)
$$

\section{RESULTADOS E DISCUSSÃO}

\section{Temperatura e umidade relativa do ar}

Enquanto as temperaturas máxima e mínima cresceram, a umidade relativa do ar caiu, do primeiro para o último período estudado (Tabela 1) o que, certamente, alterou o padrão das respostas fisiológicas das aves no intuito de manter a homeotermia e, sem dúvida, as perdas sensíveis representadas pela condução, radiação e convecção passaram a ter menor importância que as perdas latentes. Comportamento semelhante foi descrito por Macari et al. (1994).

Observa-se, na Tabela 1, que a temperatura média no período de 12 a 18 e de 19 a 38 dias de vida das aves esteve dentro da zona de conforto térmico sugerida por Baêta \& Souza (1997) mas, entre o período de 39 a 46 dias, quando as aves são mais exigentes em termos de conforto térmico, a temperatura ficou 
Tabela 1. Temperaturas diárias máxima e mínima e umidade relativa do ar, durante as três fases experimentais ${ }^{1}$

\begin{tabular}{lccc}
\hline \multirow{2}{*}{ Médias } & \multicolumn{3}{c}{ Idade das aves (em dias) } \\
\cline { 2 - 4 } & $12-18$ & $19-38$ & $39-46$ \\
\hline Temperatura máxima, $\left({ }^{\circ} \mathrm{C}\right)$ & 30,57 & 30,75 & 32,00 \\
Temperatura mínima, $\left({ }^{\circ} \mathrm{C}\right)$ & 23,88 & 23,68 & 24,50 \\
Umidade relativa do ar, $(\%)$ & 85,11 & 64,64 & 61,5 \\
\hline
\end{tabular}

acima da zona de termoneutralidade, mas não ultrapassou o limite crítico superior, também sugerido por esses autores. Quanto à temperatura máxima, tem-se que em todos os períodos analisados ela esteve acima da zona de termoneutralidade, demonstrando a necessidade de se utilizar mecanismos artificiais de controle do ambiente para que, durante este período, as aves não passem por estresse térmico. Quanto à umidade relativa, no período de 12 a 18 dias ela esteve superior à ideal, o que pode dificultar a troca de calor entre a ave e o ambiente e, nos outros períodos, manteve-se dentro da faixa recomendada (Baeta \& Souza, 1997; Mota, 2001).

A temperatura considerada ideal para o crescimento de frangos de corte é gradualmente reduzida de $32{ }^{\circ} \mathrm{C}$ no primeiro dia, para cerca de 24 a $21^{\circ} \mathrm{C}$ na quarta semana (Yalcin et al., 1997), ou 20 a $22^{\circ} \mathrm{C}$ (Rostagno, 1995). No presente experimento ocorreu o oposto, ou seja, os valores obtidos para as médias de temperaturas ficaram ainda maiores da quarta semana de vida em diante. Este fato pode ter contribuído para afetar o desempenho das aves e, concomitantemente, aumentar o consumo de água, prejudicando a qualidade da cama.

A necessidade de se manter o balanço hídrico e a homeotermia com o aumento da temperatura ambiental estimulou, provavelmente, o aumento do consumo e da perda de água pelas vias respiratórias e pelas excretas, sobretudo para o grupo de frangos alojados em mais alta densidade. Esta observação é reforçada pelos resultados de Ribeiro et al. (2004) que, trabalhando com frangas de 7 a 12 e de 13 a 18 semanas de idade, observaram que o aumento do volume de água consumida resultou também em aumento da água e redução da matéria pré-seca fecal, isto é, as excretas se tornaram mais úmidas à medida que a ingestão de água aumentava. Segundo os autores, isto pode ter implicações sobre a qualidade do ambiente para as aves.

\section{Desempenho produtivo das aves}

O consumo de ração (Tabela 2) foi afetado $(\mathrm{P}<0,05)$ pelo tipo de bebedouro apenas na fase inicial e o melhor resultado foi obtido com o bebedouro alternativo.

$\mathrm{O}$ aumento da densidade de 10 para 14 aves $\mathrm{m}^{-2}$ reduziu significativamente o consumo $(\mathrm{P}<0,05)$ nos períodos de 19-38, 39-46 dias e no período total, que caiu, em média, 4,44\%. Considerando-se que a competição por água e ração deixou de existir, visto que cada boxe contava com um comedouro e bebedouro com suficiente capacidade para atender à maior proporção de aves que a presente nas parcelas, vê-se que a principal explicação para este resultado foi o desconforto ocasionado pelo aumento da temperatura ambiente agravada pela alta densidade. Segundo Yalcin et al. (1997), a redução do consumo se trata de uma forma dos frangos de corte evitarem
Tabela 2. Consumo de ração $\left(\mathrm{g} \mathrm{dia}^{-1}\right)$ de frangos de corte em três fases e período total de criação em função do tipo de bebedouro e densidade adotada

\begin{tabular}{cccccc}
\multirow{2}{*}{ Fase } & Densidade & \multicolumn{2}{c}{ Consumo de Ração $\left(\mathrm{g} \mathrm{dia}^{-1}\right)^{1}$} & \multirow{2}{*}{ CV (\%) } \\
\cline { 3 - 5 } & & BALT & BP & Média & \\
\hline \multirow{4}{*}{$12-18$} & D10 & 62,90 & 61,60 & 62,25 & \\
& D14 & 67,00 & 56,26 & 61,63 & \\
& Média & $64,95 \mathrm{a}$ & $58,93 \mathrm{~b}$ & 61,94 & 9,056 \\
\hline \multirow{4}{*}{$19-38$} & D10 & 125,66 & 118,46 & 122,06 & \\
& D14 & 124,75 & 120,79 & 122,77 & \\
& Média & 122,06 & 122,77 & 122,41 & 5,359 \\
\hline \multirow{4}{*}{$39-46$} & D10 & 162,12 & 157,25 & $159,69 \mathrm{~A}$ & \\
& D14 & 149,46 & 149,55 & $149,50 \mathrm{~B}$ & \\
& Média & 155,79 & 153,84 & 154,81 & 4,112 \\
\hline \multirow{4}{*}{ Total } & D10 & 126,84 & 124,83 & $125,84 \mathrm{~A}$ & \\
& D14 & 121,08 & 119,44 & $120,26 \mathrm{~B}$ & \\
& Média & 123,98 & 122,14 & 123,06 & 3,842 \\
\hline
\end{tabular}

$\overline{a, b}$ Média seguida de diferentes letras minúsculas na linha, diferem pelo teste de Tukey $(\mathrm{P}<0,05)$ ${ }_{A, B}$ Médias seguidas de diferentes letras maiúsculas na coluna, diferem pelo teste de Tukey $(\mathrm{P}<0,05)$ ${ }^{1}$ BALT - Bebedouro alternativo; BP - Bebedouro pendular

$\mathrm{D} 10=$ densidade de 10 aves $\mathrm{m}^{-2} ; \mathrm{D} 14=14$ aves $\mathrm{m}^{-2}$

o excesso de calor, sempre que são expostos a elevadas temperaturas ambientais.

$\mathrm{O}$ resultado deste trabalho discorda com o obtido por Mizubuti et al. (1994) que, trabalhando com as densidades de 10, 12 e 14 aves $\mathrm{m}^{-2}$, observaram aumento no consumo de ração. É provável que tais discordâncias estejam relacionadas com as diferenças de temperaturas, por ocasião da realização dos ensaios. No estudo de Mizubuti et al. (1994) a temperatura média de $18,8^{\circ} \mathrm{C}$ foi inferior à verificada no presente trabalho, de $27^{\circ} \mathrm{C}$.

Não ocorreu efeito do bebedouro sobre o ganho de peso das aves $(P>0,05)$ em nenhum dos períodos estudados (Tabela 3); entretanto, o aumento da densidade reduziu significativamente $(\mathrm{P}<0,05)$ o ganho, no período de 19-38 dias e no período total de criação, em que a queda foi, em média, de

Tabela 3. Ganho de peso (g dia) de frangos de corte em três fases e período total de criação, em função do tipo de bebedouro e densidade adotada

\begin{tabular}{|c|c|c|c|c|c|}
\hline \multirow{2}{*}{$\begin{array}{l}\text { Fase } \\
\text { (dias) }\end{array}$} & \multirow{2}{*}{$\begin{array}{l}\text { Densidade } \\
\left({\left.\text { aves } \mathrm{m}^{-2}\right)}^{-2}\right.\end{array}$} & \multicolumn{3}{|c|}{ Ganho de Peso $\left(\mathrm{g}_{\text {ave }}{ }^{-1} \mathrm{dia}^{-1}\right)^{1}$} & \multirow[b]{2}{*}{$\mathrm{CV}(\%)$} \\
\hline & & BALT & $\mathrm{BP}$ & Média* & \\
\hline \multirow{3}{*}{$12-18$} & D10 & 39,44 & 39,80 & 39,62 & \\
\hline & D14 & 38,80 & 38,90 & 38,85 & \\
\hline & Média & 39,12 & 39,35 & 39,24 & 3,600 \\
\hline \multirow{3}{*}{$19-38$} & D10 & 53,76 & 54,58 & $54,17 \mathrm{~A}$ & \\
\hline & D14 & 52,03 & 52,10 & $52,07 \mathrm{~B}$ & \\
\hline & Média & 52,89 & 53,34 & 53,12 & 4,107 \\
\hline \multirow{3}{*}{$39-46$} & D10 & 60,75 & 54,25 & 57,50 & \\
\hline & D14 & 56,98 & 53,72 & 55,35 & \\
\hline & Média & 58,86 & 53,99 & 56,42 & 9,722 \\
\hline \multirow[t]{3}{*}{ Total } & D10 & 55,93 & 54,76 & $55,35 \mathrm{~A}$ & \\
\hline & D14 & 53,89 & 53,19 & $53,54 \mathrm{~B}$ & \\
\hline & Média & 54,91 & 53,98 & 54,45 & 2,721 \\
\hline D10 & 19 & aiúsculas 1 & $\begin{array}{l}\text { luna, difere } \\
\text { ndular }\end{array}$ & & \\
\hline
\end{tabular}


$3,27 \%$. Este resultado também discorda dos obtidos por Mizubuti et al. (1994) e novamente parece refletir as diferenças climáticas entre os ensaios.

As aves do tratamento BALT apresentaram pior conversão alimentar na fase de 12 a 18 dias de idade $(\mathrm{P}<0,05)$ em relação à obtida no tratamento BP (Tabela 4). Dois fatores podem estar relacionados a este resultado: a não apresentação prévia do equipamento aos pintos ou a maior dificuldade de acesso deles à água, em virtude do equipamento apresentar borda de cerca de $6 \mathrm{~cm}$ de altura. Os resultados nos períodos subseqüentes parecem confirmar essas hipóteses, embora Macari (1996) tenha comentado que a forma de apresentação da água tem pouca relevância em comparação com a necessidade fisiológica, pois o que influencia é o comportamento exploratório da ave, em função da necessidade de sobrevivência.

Tabela 4. Conversão alimentar de frangos de corte em três fases e período total de criação, em função do tipo de bebedouro e densidade adotada

\begin{tabular}{|c|c|c|c|c|c|}
\hline \multirow{2}{*}{$\begin{array}{l}\text { Fase } \\
\text { (dias) }\end{array}$} & \multirow{2}{*}{$\begin{array}{l}\text { Densidade } \\
\left(\text { aves } \mathrm{m}^{-2}\right)\end{array}$} & \multicolumn{3}{|c|}{ Conversão Alimentar $\left(\mathrm{Kg} \mathrm{Kg}^{-1}\right)^{1}$} & \multirow[b]{2}{*}{$\mathrm{CV}(\%)$} \\
\hline & & BALT & $\mathrm{BP}$ & Média & \\
\hline \multirow[t]{3}{*}{$12-18$} & D10 & 1,599 & 1,546 & 1,573 & - \\
\hline & D14 & 1,728 & 1,445 & 1,586 & - \\
\hline & Média & $1,663 \mathrm{a}$ & $1,496 b$ & 1,579 & 9,064 \\
\hline \multirow[t]{3}{*}{$19-38$} & D10 & 2,341 & 2,287 & 2,314 & - \\
\hline & D14 & 2,278 & 2,321 & 2,300 & - \\
\hline & Média & 2,310 & 2,304 & 2,307 & 6,842 \\
\hline \multirow[t]{3}{*}{$39-46$} & D10 & 2,701 & 2,906 & 2,803 & - \\
\hline & D14 & 2,645 & 2,808 & 2,726 & - \\
\hline & Média & 2,673 & 2,857 & 2,765 & 9,722 \\
\hline \multirow[t]{3}{*}{ Total } & D10 & 2,271 & 2,265 & 2,268 & - \\
\hline & D14 & 2,247 & 2,246 & 2,246 & - \\
\hline & Média & 2,259 & 2,256 & 2,258 & 4,344 \\
\hline
\end{tabular}

A densidade não afetou a conversão alimentar em nenhuma das fases e no período total estudado $(\mathrm{P}>0,05)$. Este resultado concorda com os obtidos por Mizubuti et al. (1994). Nenhuma mortalidade de aves foi registrada entre os tratamentos.

$\mathrm{Na}$ avaliação de carcaça não ocorreu efeito do tipo de bebedouro nem da densidade sobre os rendimentos de carcaça, peito com osso, coxa e sobrecoxa. Foi moderado o aumento da gordura abdominal, de 2,36 para $2,52 \%$ em relação ao peso vivo, da menor para a maior densidade mas a gordura abdominal cresceu significativamente $(\mathrm{P}<0,50)$ de 2,27 para $2,61 \%$ com o uso, respectivo, dos bebedouros alternativo e pendular.

O bebedouro alternativo, por ser mais atrativo aos frangos estimulou, provavelmente, maior ingestão de água, proporcionando melhor manutenção do balanço hídrico e térmico que o pendular, contribuindo para controlar a deposição de gordura abdominal das aves. Segundo Baziz et al. (1996) e Geraert et al. (1996), o desconforto térmico é um dos fatores mais relevantes no aumento na deposição de gordura na carcaça de frangos de corte.
Outros trabalhos precisam ser realizados a fim de comprovar esta observação, em virtude do recente interesse dos consumidores na redução da ingestão de gordura saturada, em face da associação com o surgimento de doenças cardiovasculares em seres humanos (Silva et al., 2003).

\section{Análise econômica}

A renda bruta média (RBM), o custo médio de arraçoamento (CMA), a margem bruta média (MBM), a rentabilidade média (RM) e o índice relativo de rentabilidade (IRR), obtidos no BPD14, BALT10 e BALT14, foram comparados com o BPD10, utilizado como padrão. Os índices do BALT foram comparados com os do BP e os da D14 com os da D10 (Tabela 5).

Tabela 5. Análise econômica ${ }^{1} \mathrm{em}$ relação ao ganho de peso das aves de 12 a 46 dias de idade de frangos de corte

\begin{tabular}{|c|c|c|c|c|c|}
\hline Tratamento $^{2}$ & $\mathrm{RBM}$ & CMA & MBM & $\mathrm{RM}$ & IRR \\
\hline BPD10 & 4,275 & 3,372 & 0,903 & 26,779 & 100,00 \\
\hline BPD14 & 4,204 & 3,296 & 0,908 & 27,548 & 102,87 \\
\hline BALTD10 & 4,311 & 3,397 & 0,914 & 26,906 & 100,47 \\
\hline BALTD14 & 4,240 & 3,322 & 0,918 & 27,634 & 103,19 \\
\hline $\mathrm{BP}$ & 4,221 & 3,322 & 0,899 & 27,062 & 100,00 \\
\hline BALT & 4,294 & 3,372 & 0,922 & 27,343 & 101,04 \\
\hline D10 & 4,328 & 3,423 & 0,905 & 26,438 & 100,00 \\
\hline D14 & 4,187 & 3,271 & 0,916 & 28,003 & 105,92 \\
\hline
\end{tabular}

A melhor RBM dos bebedouros, considerando-se as duas densidades, foi obtida com o BALTD 10 , sendo $0,84 \%$ superior à média observada com o BPD10, enquanto o BPD14 e o BALTD14 foram 1,7 e 0,8\% inferior ao BPD10, respectivamente. Tendo em vista a RBM dos bebedouros, nota-se que o BALT foi superior em $1,7 \%$ ao BP e a densidade D10 o foi em 3,3\% a D14. Esses resultados refletem a redução no ganho de peso com o uso do BP ou a densidade de 14 aves $\mathrm{m}^{-2}$.

O custo médio de arraçoamento (CMA) foi maior por ordem: para o BALTD10, em 0,74\%, enquanto o BALTD14 e BPD14 apresentaram, respectivamente, 1,5 e 1,7\%, de menor custo em relação ao BPD10 (controle). Considerando-se apenas o tipo de bebedouro, o CMA foi 1,5\% maior com o BALT em relação ao BP enquanto a D14 apresentou menor CMA em comparação com a D10.

A margem bruta média (MBM) do BALTD14 foi, em média, $1,7 \%$, do BALTD 10 foi 1,2\% e o BPD14 foi 0,6\% acima do BPD10; então, apenas nos bebedouros se observa que a MBM foi 2,5\% superior no BALT em comparação com o BP e a densidade de 10 aves $\mathrm{m}^{-2}$ foi superior em $1,2 \%$ a densidade de 14 aves $\mathrm{m}^{-2}$.

A rentabilidade média (RM) do BALTD14 foi 3,2\%, do BPD14 foi $2,87 \%$ e do BALTD 10 0,5\% superior ao do BPD10, refletindo o maior ganho de peso apresentado pelos frangos, nesses tratamentos. A RM do BALT foi cerca de $1 \%$ superior ao BP, enquanto a RM obtida na densidade de 14 aves $\mathrm{m}^{-2}$ foi $5,9 \%$ maior que a obtida na densidade de 10 aves $\mathrm{m}^{-2}$.

Apesar de promover maior custo com o arraçoamento, o uso do bebedouro alternativo na densidade de 14 aves $\mathrm{m}^{-2}$ 
influenciou um índice relativo de rentabilidade (IRR) 3,2\% superior ao do bebedouro pendular na densidade de 10 aves $\mathrm{m}^{-2}$, enquanto o IRR do BPD14 foi $2,9 \%$ e o BALTD10 foi $0,5 \%$ superior ao BPD10. O IRR obtido com o BALT foi $1 \%$ acima do obtido com BP e o obtido com a densidade de 14 aves $\mathrm{m}^{-2}$ foi $5,9 \%$ superior ao obtido com a densidade de 10 aves $\mathrm{m}^{-2}$. Os maiores IRR obtidos com o BALT e o D14 em relação ao BP e D10 refletem, respectivamente, a maior eficiência de ganho de peso dos frangos em relação à ração ingerida, aumentando o retorno com a venda das aves.

\section{CONCLUSÕES}

1. O bebedouro alternativo não afeta o desempenho de frangos de corte em condições de criação em ambiente natural quente, podendo substituir o bebedouro pendular.

2. A densidade de 14 aves $\mathrm{m}^{-2}$ apresenta índice relativo de rentabilidade $5,9 \%$ superior à densidade de 10 aves $\mathrm{m}^{-2}$, enquanto o bebedouro alternativo indica índice relativo de rentabilidade $1 \%$ acima do bebedouro pendular.

3. Os resultados do presente trabalho recomendam o uso do bebedouro pendular em regiões de clima quente e mais estudos devem ser realizados visando compreender melhor as implicações do uso deste equipamento sobre o desempenho de frangos de corte.

\section{LITERATURA CITADA}

Baêta, F.C.; Souza, C.F. Ambiência em edificações rurais conforto animal. Viçosa: Editora da UFV, 1997, 246p.

Balnave, D. Challenges of accurately defining the nutrient requirement of heat-stressed poultry. Poultry Science, Champaign, v.83, n.1, p.5-14. 2004.

Bampi, R. Manejo no período de calor. In: FACTA. Manejo de frangos. Campinas,SP: Editora FACTA, 1994. p.91-102.

Baziz, H.A.; Geraert, P.A.; Padilha, J.C.F.; Guillaumin, S. Chronic heat exposure enhances fat deposition and modifies muscle and fat repartition in broiler carcasses. Poultry Science, Champaign, v.75, n.4, p.505-513, 1996.

Daghir, N.J. Poultry production in hot climates. Wallingford: CABI, 1995.303p.

Geraert, P.A.; Padilha, J.C.F.; Guillaumin, S. Metabolic and endocrine changes induced by chronic heat exposure in broiler chickens: growth performance, body composition and energy retention. British Journal of Nutrition, Wallingford, v.75, n.2, p.195-204, 1996.

Guidoni, A.L. Alternativas para comparar tratamentos envolvendo o desempenho nutricional animal. Piracicaba: ESALQ-USP, 1994. 105p. Tese Doutorado
Macari, M. Água na avicultura industrial. Jaboticabal: FUNEP/ UNESP, 1996. 128p.

Macari, M.; Furlan, R. L.; Gonzales, E. Fisiologia aviária aplicada a frangos de corte. Jaboticabal: FUNEP/UNESP, 1994. 246p.

Mathur, P.K.; Horst, P. Genotype by environment interactions in laying hens based on relationship between breeding values of sires in temperate and tropical environments. Poultry Science, Champaign, v.73, n.8, p.1777-1784, 1994.

Mizubuti, I.Y.; Fonseca, N.A.N.; Pinheiro, J.W. Desempenho de duas linhagens comerciais de frangos de corte, criadas sob diferentes densidades populacionais e diferentes tipos de camas. Revista da Sociedade Brasileira Zootecnia, Viçosa, v.23, n.3, p.476-484, 1994.

Mota, F.S. Climatologia zootécnica. Pelotas: Edição do autor. 2001. 140p.

Nääs, I. de A. Estresse calórico - meios artificiais de condicionamento. In: Simpósio Internacional de Ambiência e Instalações na Avicultura Industrial, v.1, 1995, Campinas. Anais ... Campinas: FACTA, 1995, p.109-112.

Ribeiro, M.L.G.; Silva, J.H.V.; Rocha, M.R.F.; Silva, J. L; Silva, M. B. S.; Silva, E. L. S.; Efeito do sódio sobre o consumo de água e o desempenho de frangos de 13 a 18 semanas de idade. In: Suplemento da Revista Brasileira de Ciência Avícola, v.6, 2004, Campinas. Resumo ... Campinas: FACTA, 2004.p. 115

Rostagno, H.S. Programas de alimentação e nutrição para frangos de corte adequados ao clima. In: Simpósio Internacional de Ambiência e Instalação na Avicultura Industrial. 1995, Campinas. Anais ... Campinas: FACTA, 1995. p.11-20.

UFV - Universidade Federal de Viçosa. SAEG - Sistema de análises estatísticas e genéticas, Versão 7.1, Viçosa: UFVCPD, 2000.

Silva, J.H.V.; Albino, LFT.; Nascimento, AH. Estimativas da composição anatômica da carcaça de frangos de corte com base no nível de proteína da ração e peso da carcaça. Revista Brasileira de Zootecnia, Viçosa, v.32, n.2, p.354-363, 2003.

Silva, J.H.V.; Vieira, M.A.B.; Silva, E.M.; Silva, E.L.; Jordão Filho, J.; Ribeiro, M.L.G.; Rocha, M.R.F.; Santos, J.L.; Silva, A.C.; Lima, M.R.; Araújo, J.A.; Santos, J.G.; Cruz, F.F.F.S.; Ramos, J.C.; Silva, A.L.; Medeiros, L.C. Efeito do bebedouro e do programa de alimentação sobre o desempenho pré-inicial e inicial de pintos de corte. In: Reunião anual da SBZ, 41. 2004, Campo Grande. Anais ... Campo Grande,MS: SBZ, 2004. CD-Rom

Yalcin, S.; Settar, P.; Ozkan, S.; Cahaner, A. Comparative evaluation of three commercial broiler stocks in hot versus temperate climates. Poultry Science, Champaign, v.76, n.7, p.921-929, 1997. 